\title{
Effect of Friction Stir Welding on Mechanical Properties and Fracture Mechanism of 7B52 Al Laminated Composite
}

\author{
Yushan $\mathrm{CHEN}^{1, \mathrm{a}}$, Hongyu $\mathrm{SUN}^{1}$, Xinrui MA ${ }^{1}$ \\ ${ }^{1}$ School of Materials Science and Engineering, Nanjing \\ University of Science and Technology \\ Nanjing, China \\ e-mail: ${ }^{a}$ chen_yushan@foxmail.com
}

\author{
Qi ZHOU ${ }^{1,2, b^{*}}$, Hao XIA ${ }^{2}$, Shubiao QIU ${ }^{2}$ \\ ${ }^{2}$ Jingjiang Robot Intelligence Manufacturing (Welding) \\ Center \\ Taizhou, China \\ e-mail: ${ }^{b}$ cheezhou@126.com
}

\author{
Chongbin TANG ${ }^{3}$ \\ ${ }^{3}$ Zhonghui Welding Intelligence Technology Co., Ltd \\ Foshan, China
}

\begin{abstract}
Aluminum laminated composite (ALC) is a new type of structural material with a broad application space and development prospects. Due to the laminated structure, the mechanical properties and failure patterns of ALCs differ significantly from those of uniform materials. The friction stir welding (FSW) of Al alloy can effectively avoid many defects caused by fusion welding, but the FSW of ALCs is in its infancy stage. Friction stir welding experiment of 7B52 ALC was carried out in this study. The Vickers hardness test, tensile test and impact test were performed on the specimens of the joint and base metal to analyze the effect of friction stir welding on microhardness, tensile properties and impact properties. The fracture surfaces were observed by SEM to investigate the fracture mechanism. A defect free weld was obtained. However, the laminated structure was destroyed, resulting in the decrease of microhardness and tensile strength. The microstructure of the weld was improved, significantly increasing the impact toughness.
\end{abstract}

Keywords-friction stir welding; laminated composite; microhardness; tensile properties; impact properties

\section{INTRODUCTION}

Aluminum alloy is widely used in aerospace, marine, transport vehicle, military industry and other fields due to its low density and high specific strength. However, with the development of science and technology and the emergence of various new industries, it is increasingly difficult for a single material to satisfy the requirements of production. As a result, composite materials made of different metals or alloys with special structures and higher properties have attracted more and more attention [1-3].

Al laminated composite (ALC) consists of two or more different aluminum alloys [4]. It is produced by rolling, casting and other manufacturing processes to achieve metallurgical bonding on the interface [5]. A novel $\mathrm{Al}$ matrix $\mathrm{Ca}$ reinforced nanocomposites was developed by Tian et al $[6,7]$ using powder metallurgy and severe deformation processing (i.e. extrusion, swaging and wire drawing) to achieve metallurgical bonding at metallic interfaces with high strength, high electrical conductivity. They also developed a general strengthening model for metal matrix composite based on the strengthening from interfaces using the strain gradient concept [8].Compared with traditional Al alloys, ALCs are superior in strength, ductility and impact resistance $[9,10]$. They also bear excellent particular performances, such as ballistic protection, blast mitigation, thermal management, heat exchange and vibration damping [11]. Besides, the mechanisms of deformation and fracture of laminated composites differ greatly from those of uniform materials [12]. The interfaces between metallic-intermetallic layers result in the deviation and deceleration of propagating cracks, increasing the reliability of the material [13]. For examples, Pu et al. $[14,15]$ investigated multilayered steel composite using the crystal plasticity finite element method. Their study indicated that the enhanced load transfer effectiveness resulted in excellent performance of this composite-type metallic material in terms of strength and ductility. A stress corrosion intergranular cracking at the grain boundary interfaces was studied by their diffusioncoupled cohesive zone model $[15,16]$.

The joining of ALC is of great importance for its utilization in all fields. However, when it comes to fusion welding, ALC is accompanied by the same defects of traditional $\mathrm{Al}$ alloys like porosity and cracks as well as large residual stress and deformation. For example, the defects and damages in composites like porosity and cracks can be imaged and detected by an advanced technique developed by He et al $[17,18]$ using guided waves to estimate the defect reflectivity, which can be converted to Young's modulus or stiffness in the damage region. Besides, the pre-welding preparation was complicated in order to remove hydrogen, which severely reduced the efficiency of production.

The friction stir welding (FSW) can achieve joints free from these defects since melting does not take place during the welding process and the metals are joined in the solid state due to the heat generated by the friction and the material flow by the stirring [19]. Since developed at The Welding Institute (TWI) in the UK in 1991, FSW has been popularized rapidly and become the most prevalent method for the joining of $\mathrm{Al}$ alloys [20]. Nowadays, although FSW process of $\mathrm{Al}$ alloys is mature, there are few researches on friction stir welding of ALCs. 
7B52 Al laminated composite is made of two kinds of $7 \mathrm{xxx}$ series Al alloy sheets by rolling. One of them is 7A52 $\mathrm{Al}$ alloy, a kind of structural material with excellent strength, weldability and defensible performance which is developed in China and applied in armored vehicles [21, 22]. Friction stir welding of 7A52 Al alloy has been explored by several researchers in recent years and optimized process parameters for various thicknesses of plates have been acquired [23-26].

In this paper, mechanical properties of the base metal and friction stir welded joint of 7B52 laminated Al alloy are tested to analyze the effect of FSW on the properties of ALCs. Proper welding process will play an important role in the popularization of ALCs.

\section{EXPERIMENTAL PROCEDURE}

Welding was performed on 7B52 ALC plates with the dimensions of $12 \mathrm{~mm} \times 150 \mathrm{~mm} \times 500 \mathrm{~mm}$ in a butt joint configuration. Fig. 1 shows the schematic illustration of the laminated structure of the ALC plate with 3 layers. The thicknesses of L1, L2 and L3 were $3 \mathrm{~mm}, 3 \mathrm{~mm}$ and $6 \mathrm{~mm}$, respectively. Between adjacent layers was interlamellar (IL) material with the thickness lower than $0.1 \mathrm{~mm}$. According to the EDS analysis, the chemical composition of each layer is shown in table 1.

The FSW experiment was carried out on a gantry friction stir welding machine (FSW-LM-025-2030). A conical threaded welding tool made from tool-steel with a shoulder diameter of $24 \mathrm{~mm}$ and a probe diameter of $12 \mathrm{~mm}$ was used with tool tilt angle of $2.5^{\circ}$. The welding tool rotated in a counter-clockwise direction at a rotational speed of 500 $\mathrm{r} / \mathrm{min}$ and simultaneously traversed along the weld line at a speed of $150 \mathrm{~mm} / \mathrm{min}$.

The Vickers hardness test was carried out on a Vickers microhardness tester (HVS 1000Z) with the indenter load of $9.8 \mathrm{~N}$ and the loading time of $10 \mathrm{~s}$.

TABLE I. CHEMICAL COMPOSITION IN LAYERS (EDS DATA, WT. \%)

\begin{tabular}{|c|c|c|c|c|c|c|}
\hline Layer & Zn & Mg & Cu & Cr & Mn & Al \\
\hline L1/L2 & 4.89 & 2.50 & 0.10 & 0.17 & 0.58 & Balance \\
\hline L3 & 6.80 & 3.49 & 1.00 & 0.09 & 0.15 & Balance \\
\hline
\end{tabular}

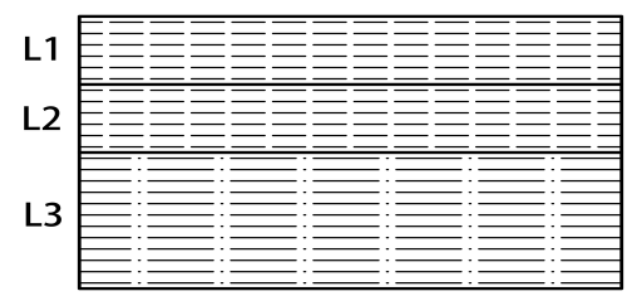

Figure 1. Schematic diagram of the laminated structure of 7B52 ALC plate.

According to ASTM E8M standard, three sub-sized tensile specimens were respectively cut from the weld and the base metal by wire-electrode cutting. In order to investigate the difference in mechanical properties between laminated alloy and traditional single-layer alloy, three specimens identical to L3 alloy on the 7B52 ALC base metal were also prepared. The test was carried out in a universal testing machine (CSS 44100).

Charpy V-notch specimens were prepared in the same way according to ASTM E23 standard and tested in an impact test machine (JB30A).

After the tensile test and impact test, the fracture surfaces of the specimens were observed by SEM.

\section{RESULTS AND DISCUSSION}

\section{A. Vickers Microhardness}

The Vickers microhardness values of the FSW joint specimen were measured in L2 and L3 on the cross section and the microhardness distribution are shown in Fig. 2. Since the first layer was too close to the edge of the sample, the microhardness was unable to be measured accurately.

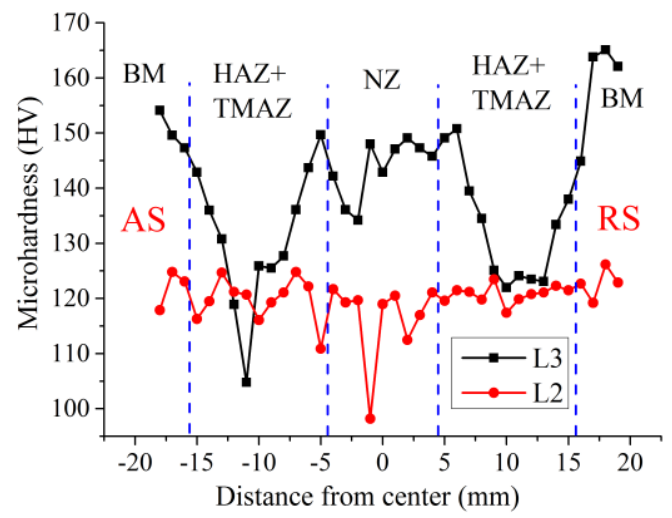

Figure 2. Microhardness in L2 and L3 of the FSW joint.

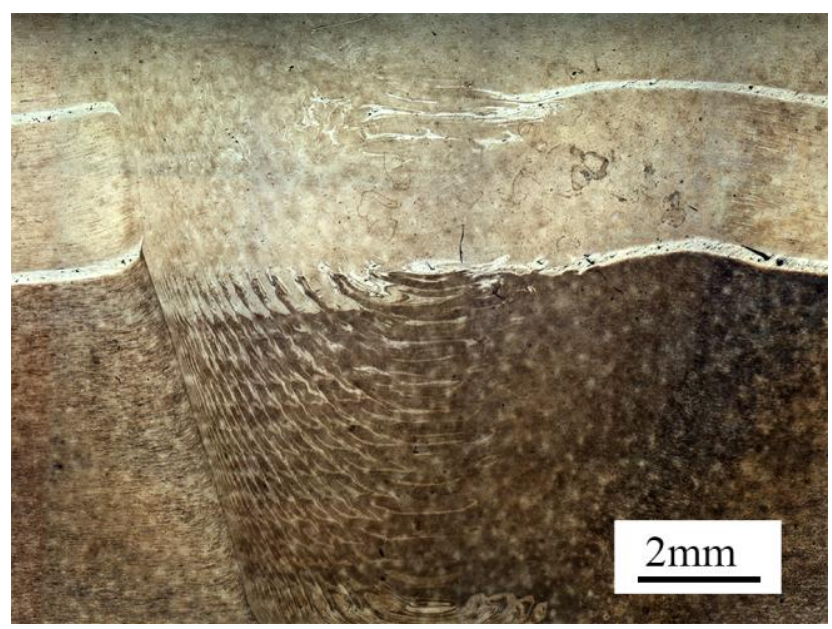

Figure 3. Macrograph of the cross section of the FSW joints.

In L3, the microhardness values in different regions of the weld are dramatically different. The microhardness in the nugget zone (NZ) is slightly lower than that of base metal, with the maximum value exceeding $90 \%$ of base metal. The microhardness in thermal-mechanical affected zone (TMAZ) and heat affected zone (HAZ) is relatively lower, especially in $\mathrm{HAZ}$ on the advancing side (AS), where the minimum 
hardness value was obtained. The grains in NZ were refined due to the dynamic recrystallization, getting the microhardness improved. In HAZ and TMAZ, the grains got coarser with the increase of temperature, resulting in lower microhardness.

In NZ, the microhardness values on the AS are apparently lower than those on the retreating side (RS). As shown in Fig. 3, the AS presents a scale like morphology, which is caused by the alternate distribution of downward L2 material flow and L3 matrix. And experimental results show that the microhardness of L2 alloy is lower than that of L3 alloy. As a result, the microhardness of L3 on the AS decreased because of the interfusion of L2 alloy. The minimum value is $135 \mathrm{HV}$, which is still higher than that of the microhardness of L2 alloy.

The hardness of L2 base metal is approximately $120 \mathrm{HV}$, which is $25 \%$ lower than that of L3 base metal. In L2, the hardness of the weld is similar to that of base metal and the values are within a narrow range. This seems to be attributed to the shoulder of the FSW tool. During the welding process, L2 was close to the shoulder. Dynamic recrystallization occurred due to the frictional heat and stirring of the shoulder and fine equiaxed grains were acquired, resulting in higher microhardness.

The microhardness values in the NZ are slightly lower than those in other regions, and the minimum values are discretely distributed in this area. As shown in Fig. 2, the laminated structure was severely destroyed and the crushed interlamellar material flowed downward into L2. The interlamellar metal is commercially pure aluminum, which has a very low hardness. The interlamellar material diffused in L2, considerably reducing the hardness of L2 matrix. If the measuring point happened to be interlamellar material, the minimum microhardness value would appear, which explained the result of the test.

\section{B. Tensile Properties}

Fig. 4 shows the tensile strength and elongation of the FSW joint, laminated base metal and L3 alloy of the base metal. The tensile strength of L3 alloy is $550 \mathrm{MPa}$. The tensile strength of laminated base metal is $475 \mathrm{MPa}$, which is $13.6 \%$ lower than that of L3 alloy. The FSW joint obtains tensile strength of $335 \mathrm{MPa}$ and joint efficiency of $70.5 \%$. The elongations of L3 alloy and laminated base metal are 5\% and $4.5 \%$ respectively while the FSW joint exhibits relatively low ductility of $2.5 \%$.

From the photograph of specimen shown in Fig. 5(a), it is discovered that the FSW joint specimen fractured on the AS of the NZ, with the crack initiated on the interface between L2 and L3. It can be seen from fig. 5(b) that the fracture of the laminated base metal sample originates from the interface between the layers.

In order to further analyze the fracture mechanism of the tensile specimens, the tensile fracture surfaces were analyzed by SEM. Fig. 6 shows the fractograph of tensile test specimen of the FSW joint. Owing to the influence of lamination, the fracture morphology varies along thickness. The region marked A in Fig. 6(a) shows the interlamellar material between L2 and L3. As shown in Fig. 6(b) at higher magnification, the fracture morphology in area A is ripple pattern, which is a typical characteristic of gliding fracture. The region marked B exhibits L2 alloy, which is shown in Fig. 6(c) at higher magnification.

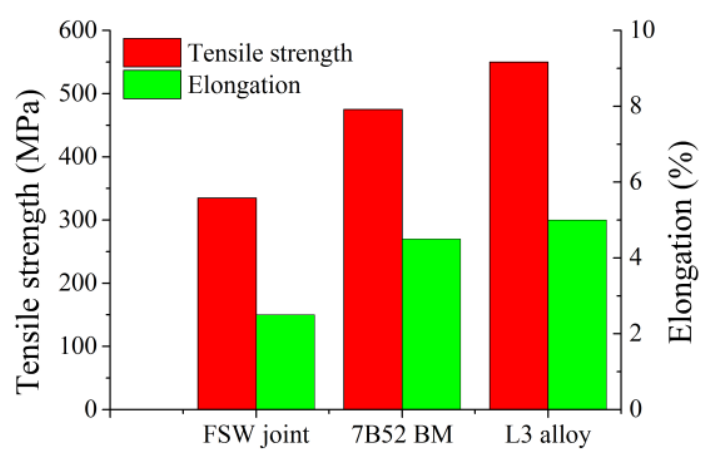

Figure 4. Results of tensile test.

A great quantity of fine equiaxed dimples exists among a few large dimples, showing characteristics of ductile fracture. Obvious secondary cracks and quasi cleavage planes representing crack propagation exists at area C. Area D consists of L1, L2 and the interlayer between them, but no interface exists on the fracture surface. It can be referred that the original laminated structure on L1 and L2 is completely destroyed, which is also shown in Fig. 3. The morphology of area $\mathrm{D}$ is similar to that of area $\mathrm{B}$, which represents ductile fracture. $\mathrm{L} 3$ region, on the left of area $\mathrm{A}$, was a crack growth area similar to $\mathrm{C}$, exhibiting a brittle fracture mode.

The failure process can be deduced from the analysis of fractograph. The crack initiated at the interlayer between L2 and L3 on the AS. As shown in Fig. 3, scale like morphology appeared on the AS of the NZ and the interlamellar material between L2 and L3 was broken. L2 alloy, L3 alloy and interlamellar material were alternately mixed and innumerable interfaces were formed. The bonding strength of dissimilar materials was influenced by many factors. Besides, the interlamellar material is $\mathrm{CP}-\mathrm{Al}$, possessing a much lower strength than matrix. Consequently, this area became the weakest place in the weld. Crack was prone to initiate at some interfaces where the bonding strength was relatively lower.

Similarly, in the area between L1 and L2, the interlamellar material was also severely broken. However, L1 alloy and L2 alloy were the same alloy, so the interface between dissimilar metals did not exist. In addition, this area was close to the shoulder during the welding process. Under the large compressive force by the shoulder, the material was compacted and the bonding strength was relatively higher.

After initiation, the crack propagated to L2 and L3 on both sides. In L3, the grains in the NZ were refined due to dynamic recrystallization, while the grains in the HAZ got coarser and the strength decreased. As a result, the crack extended towards the HAZ. The crack propagation direction was consistent with the orientation of maximum shear stress, at an angle of 45 degrees from the tensile direction, which is shown in Fig. 5(a). In the HAZ, large quantities of brittle 
second-phase particles were distributed in the grain boundaries. It can be concluded that intergranular brittle fracture was the main fracture mode in this area.

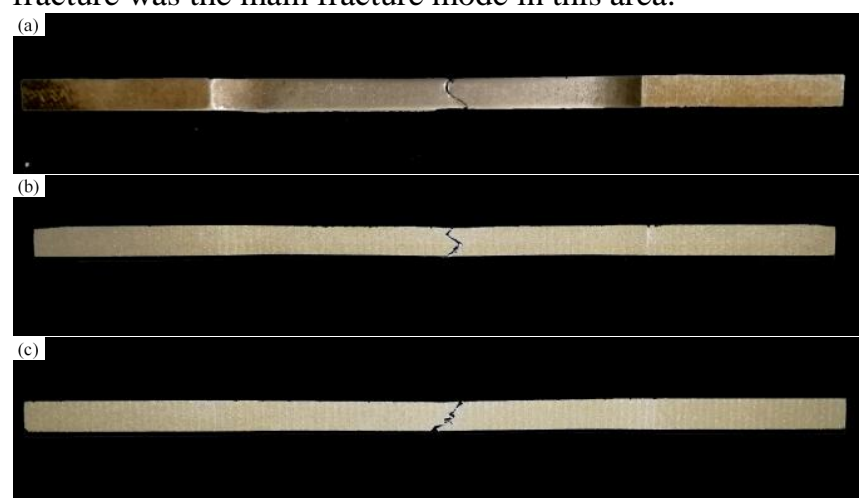

Figure 5. Photographs of fractured tensile specimens of: (a) FSW joint; (b) the base metal of 7B52 ALC; (c) L3 alloy.

As proved in microhardness test, microstructure and mechanical properties of different areas in L2 are within a narrow range. The crack extended upward in the direction perpendicular to the surface of the specimen because of the minimum expenditure of energy on this path.

As noted earlier, the interlamellar material diffused in L2 matrix in the area between L1 and L2. Pieces of interlamellar material with lower strength were the target of crack propagation. As a result, the crack propagation direction was
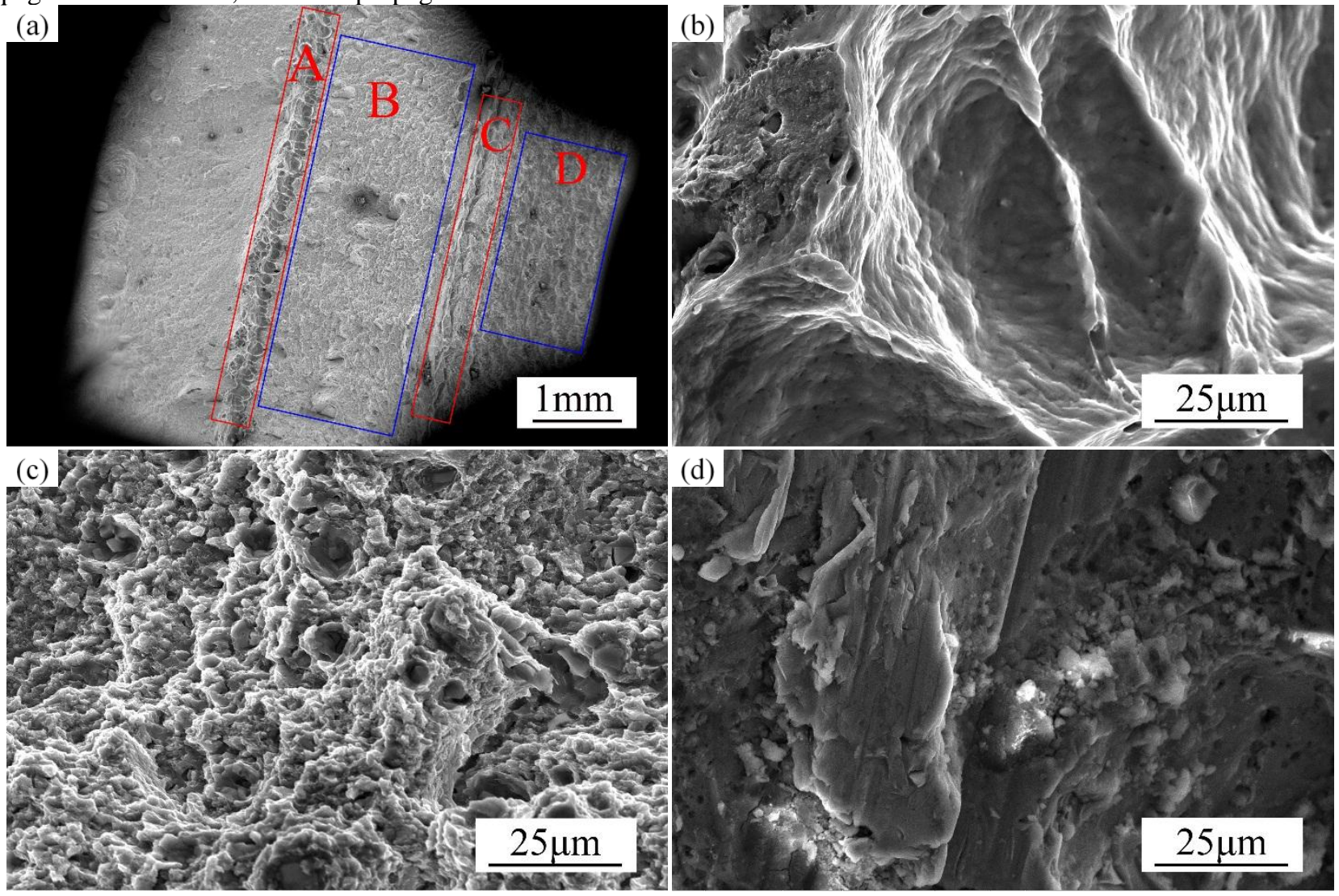

Figure 6. SEM micrographs of FSW joint after tensile test with different magnifications: (a) micrograph at lower magnification; (b, c, d) Enlarged SEM micrograph of region marked A, B and C in (a), respectively. changed and many secondary cracks appeared. Eventually, the main crack extended to the surface on an optimal path and the specimen was completely broken.

\section{Impact Properties}

The photographs of specimens after test are shown in Fig. 7, and the macrographs of fracture surface are shown in Fig 8. The red lines represent the paths of crack propagation. Fig. 7(a) shows that on the specimen of L3 alloy, the crack propagated rapidly along the direction of maximum shear stress (at an angle of $45^{\circ}$ from the direction of impact force) until getting close to the surface of the specimen. Multiple secondary cracks initiated and propagated along the length of the specimen. On the fracture surface in Fig. 8(a) exists a large area of radial fracture region representing brittle fast crack propagation. A narrow area of ductile fracture region is near the surface of the specimen, which is called shear lip. The length and width of the flat fracture region were measured with vernier caliper, and the percentage of shear fracture were calculated to be $5.4 \%$. The microstructure of L3 alloy is a typical elongated structure with the grain orientation along the rolling direction. Large amounts of second-phase particles accumulate in the grain boundaries, greatly increasing the brittleness of the grain boundaries. It is concluded that the fracture mode of L3 alloy is intergranular brittle fracture. 

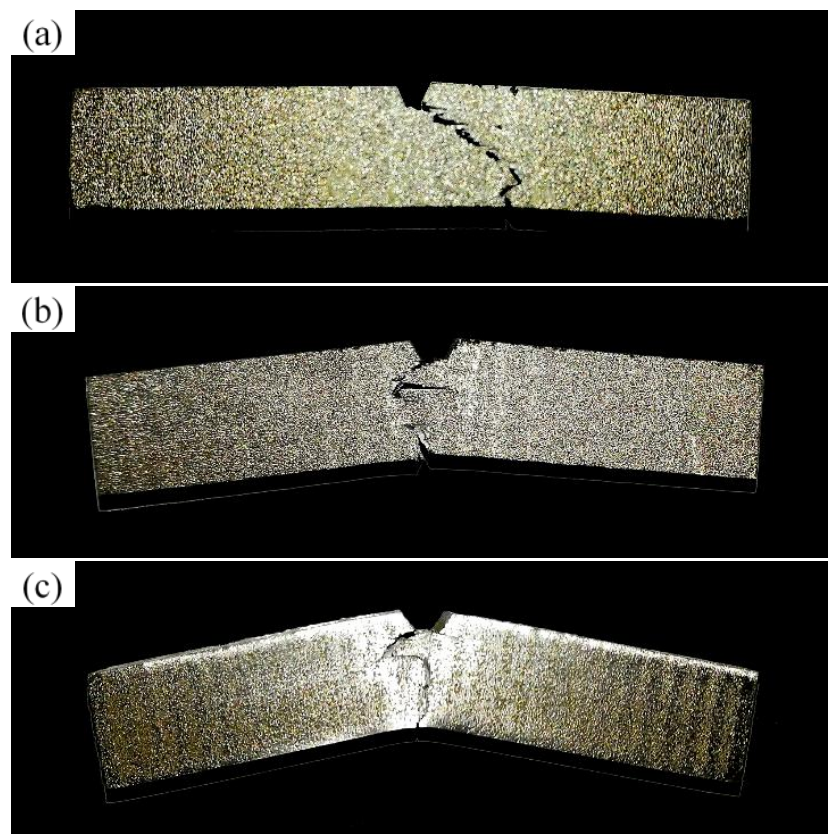

Figure 7. Photographs of fractured impact test specimens of: (a) L3 alloy; (b) the base metal of 7B52 ALC; (c) FSW joint.

As shown in Fig. 7(b), the fracture surface of the laminated base metal shows a zigzag shape. The angel between the crack propagation orientation and the direction of impact force is from 45 to 90 degrees. Similar to L3 alloy, the grain boundaries are the optimal paths of crack propagation. Fig. 8(b) depicts the macrograph of its fracture surface, which consists of 6 layers of alternate flat fracture regions and shear fracture regions. The crack propagation in L3 is the same as that of the specimen of L3 alloy, showing a large radical fracture region and a small shear fracture region. After passing through the interlamellar material between L2 and L3, the crack found new paths to extend. Then new brittle fracture region and ductile fracture region were formed in L2. This process was repeated in L1. Eventually, the laminated structure including 6 layers were formed. According to measurement and calculation, the percentage of shear fracture was $52.9 \%$. It is concluded that the interlamellar material with a higher ductility can efficiently impede the crack propagation and significantly increase the impact toughness of material.

The photograph of the specimen of the weld is shown in Fig. 7(c). The crack propagation orientation is almost identical to the direction of impact force, except for the second path in L2. This indicates that the fracture mode is different from that of base metal. As shown in the macrograph of fracture surface in Fig. 8(c), L1 and L2 were mixed together by welding while the interface between L2 and L3 still existed. Apparently, the fracture morphology of the upper layer shows a laminated structure of brittle fracture region and ductile fracture region. However, the fractograph of L3 cannot be distinguished clearly in the macrograph.

Therefore, L3 of the fracture surface was observed with SEM and the micrographs are shown in Fig. 9. The surface of L3 can be divided into 4 regions of different morphology, as shown in Fig. 9(a). In area A, as presented in Fig. 9(b), great quantities of fine equiaxed dimples and elongated dimples exist among river pattern, showing characteristics of quasi cleavage fracture. In area B, as shown in Fig. 9(c), a few large dimples are surrounded by a large amount of fine equiaxed dimples. Fig. 9(d) displays the morphology in area $\mathrm{C}$ and area $\mathrm{D}$ at higher magnification. Area $\mathrm{C}$ is filled with fine equiaxed dimples, while in area $\mathrm{D}$, large equiaxed dimples and elongated dimples are alternately distributed. Area B, C and D all present the characteristics of dimple fracture. It is concluded from the micrographs of fracture surface that the fracture mode is mainly ductile fracture. By measurement and calculation, the percentage of shear fracture was $73.2 \%, 20.3 \%$ higher than that of base metal.
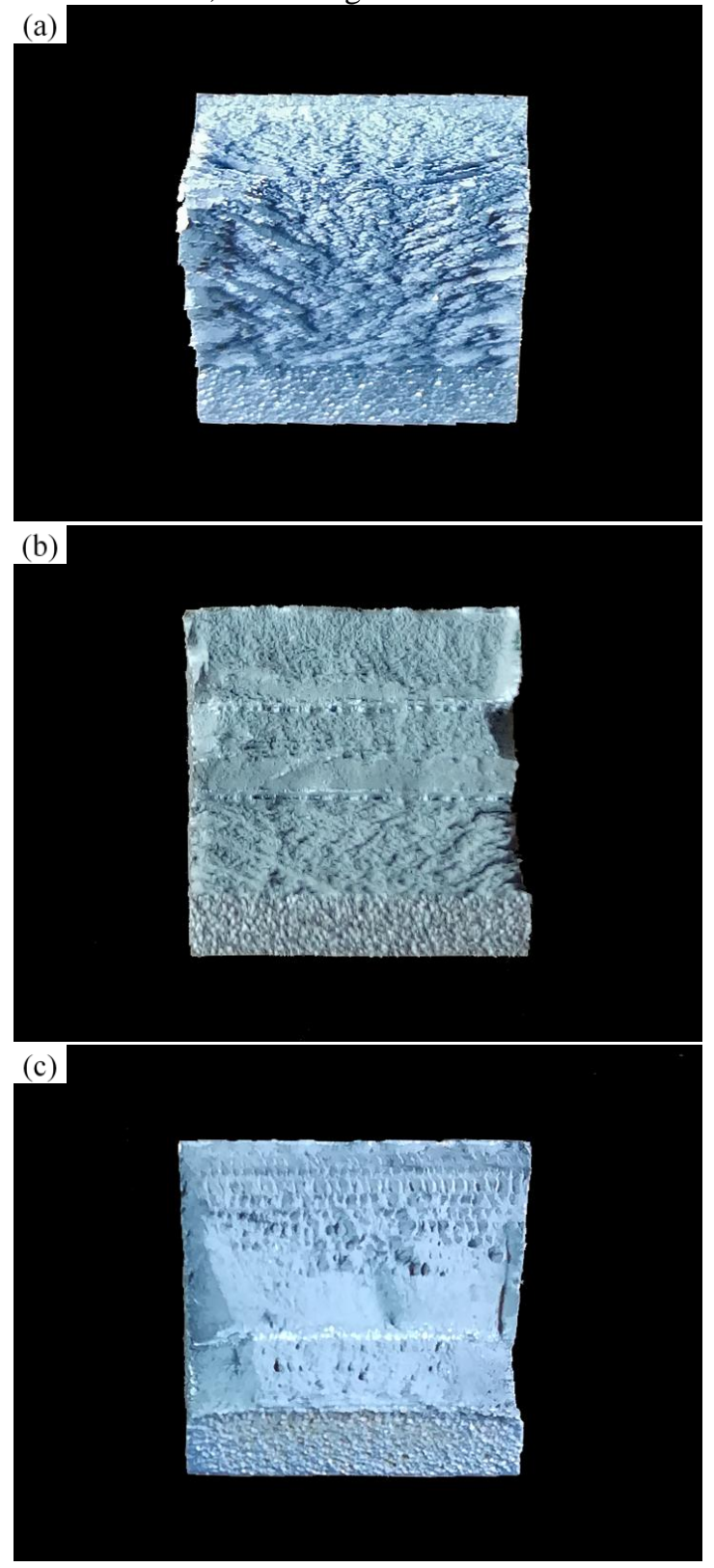

Figure 8. Macrographs of fracture surfaces of: (a) L3 alloy; (b) the base metal of 7B52 ALC; (c) FSW joint. 

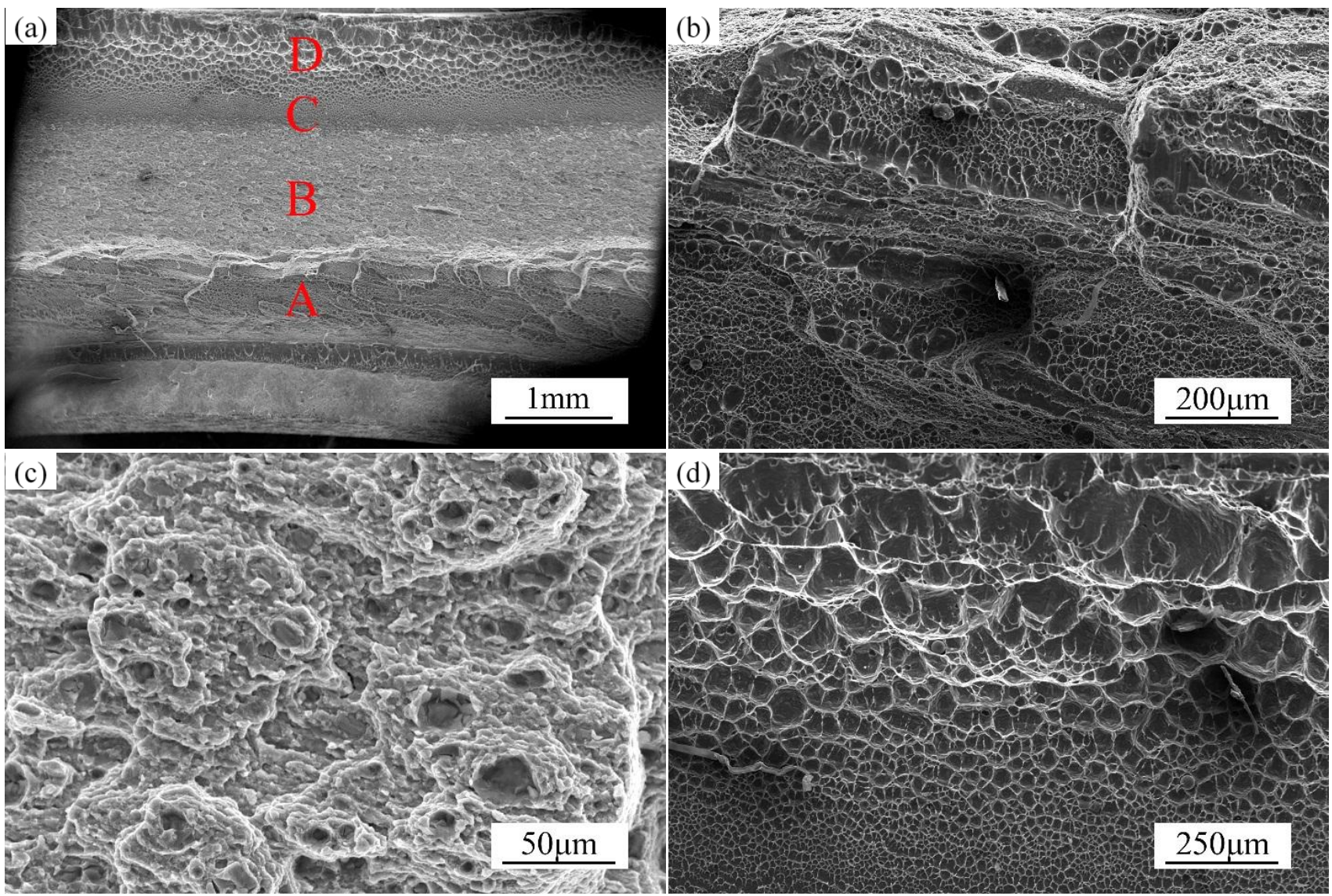

Figure 9. SEM micrographs of FSW joint after impact test with different magnifications: (a) micrograph at lower magnification; (b, c, d) Enlarged SEM micrograph of region marked A, B, C and D in (a).

The increase in ductility is directly related to the change of microstructure. Fine equiaxed grains are acquired in NZ, as shown in Fig. 10. It is due to severe plastic deformation and high temperature caused by frictional heat and stirring, leading to dynamic recrystallization. Second-phase particles which were distributed in the grain boundaries before welding now are dispersed evenly in the matrix. Furthermore, the crushed interlamellar material, $\mathrm{CP}-\mathrm{Al}$, is distributed in the matrix, increasing the ductility of the alloy.

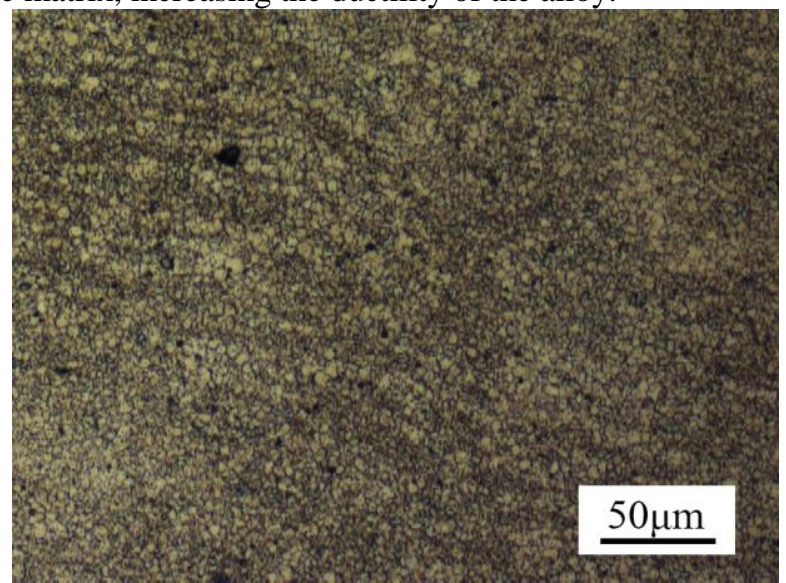

Figure 10. Optical microscope image of fine equiaxed grains in the nugget zone.

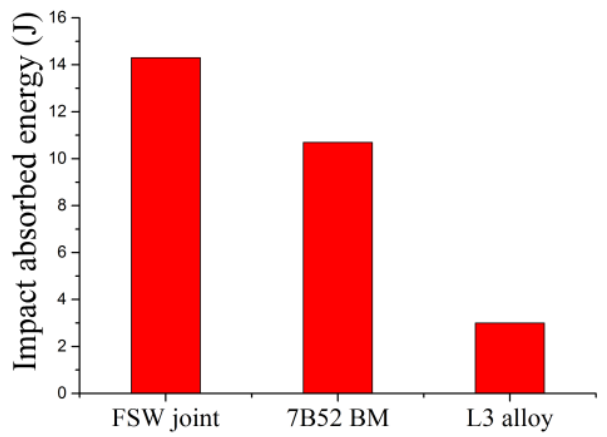

Figure 11 Results of impact test.

Fig. 11 shows the impact absorbed energy of the FSW joint, laminated base metal and L3 alloy. The impact absorbed energy of L3 alloy is $3.0 \mathrm{~J}$, showing very low impact toughness. The impact absorbed energy of laminated base metal is $10.7 \mathrm{~J}, 2.6$ times higher than that of L3 alloy. The FSW joint exhibits highest impact resistance of $14.3 \mathrm{~J}$, $33.6 \%$ higher than that of laminated base metal. It is a great improvement on the mechanical property of laminated base metal. 


\section{CONCLUSIONS}

(1) The FSW process destroyed the laminated structure of 7B52 ALC, resulting in the mixture of alloy from different layers and interlamellar material. Consequently, the microhardness of matrix in the nugget zone decreased.

(2) In the laminated base metal, the interlamellar material has the property of low strength but high ductility. It originated the crack initiation and decreased the tensile strength of material in tensile test. However, it efficiently impeded the crack propagation and significantly increased the impact toughness of material in impact test.

(3) In the region between L2 and L3 on the AS of the NZ, L2 alloy, L3 alloy and interlamellar material were alternately distributed and innumerable interfaces were formed. It is the weakest area in the weld, where the crack initiated in tensile test.

(4) After FSW, the impact toughness of 7B52 ALC was greatly increased due to the improvement of microstructure. It is of great significance for the application of this structural material.

\section{ACKNOWLEDGMENT}

This paper is supported by National Defense Basic Scientific Research Program (No. JCKY2016606B005) and Equipment Pre-Research Program (No. 41423050116).

\section{REFERENCES}

[1] W. S. Miller, L. Zhuang, J. Bottema, A. J. Wittebrood, P. D. Smet and A. Haszler, et al, "Recent development in aluminum alloys for the automotive industry," Mater. Sci. Eng., A, vol. 280, Mar. 2000, pp. 37-49, doi:10.1016/S0921-5093(99)00653-X

[2] X. P. Zhang, Y. H. Yang, J. Q. Liu, X. F. Luo and J. T. Wang, "Mechanical properties of an $\mathrm{Al} / \mathrm{Mg} / \mathrm{Al}$ tri-laminated composite fabricated by hot rolling," J. Mater. Sci, vol. 45, Mar. 2010, pp. 3457-3464, doi:10.1007/s10853-010-4373-z.

[3] X. P. Zhang, S. Castagne, T. H. Yang, C. F. Gu and J. T. Wang, "Entrance analysis of $7075 \mathrm{Al} / \mathrm{Mg}-\mathrm{Gd}-\mathrm{Y}-\mathrm{Zr} / 7075 \mathrm{Al}$ laminated composite prepared by hot rolling and its mechanical properties," Mater. Des, vol. 32, Mar. 2011, pp. 1152-1158, doi:10.1016/j.matdes.2010.10.030.

[4] B. Zhu, W. Liang and X. R. Li, "Interfacial microstructure, bonding strength and fracture of magnesium-aluminum laminated composite plates fabricated by direct hot pressing," Mater. Sci. Eng., A, vol. 528, Aug. 2011, pp. 6584-6588, doi:10.1016/j.msea.2011.05.015.

[5] M. Konieczny, "Relations between microstructure and mechanical properties in laminated Ti-intermetallic composites synthesized using $\mathrm{Ti}$ and $\mathrm{Al}$ foils," Key. Eng. Mater, vol. 592-593, Nov. 2014, pp. 728731, doi:10.4028/www.scientific.net/KEM.592-593.728.

[6] L. Tian, A. Russell, T. Riedemann, S. Mueller, I. Anderson, "A deformation-processed Almatrix/Ca-nanofilamentary composite with low density, high strength, and high conductivity", Materials Science and Engineering: A 690 (2017) 348-354.

[7] L. Tian, H. Kim, I. Anderson, A. Russell, The microstructurestrength relationship in a deformation processed $\mathrm{Al}-\mathrm{Ca}$ composite, Materials Science and Engineering: A 570 (2013) 106113.

[8] L. Tian, A. Russell, I. Anderson, A dislocation-based, strain-gradientplasticity strengthening model for deformation processed metal-metal composites, Journal of Materials Science 49(7) (2014) 2787-2794.

[9] G. X. Zhou, Y. J. Lang, J. Hao, W. Liu, S. Wang and L. Qiao, et al, "Interface analysis of 7B52 Al alloy laminated composite fabricated by hot-roll bonding," Trans. Nonferrous. Met. Soc. China, vol. 26, May. 2016, pp. 1269-1275, doi:10.1016/S1003-6326(16)64227-9.

[10] Y. Cao, C. Guo, S. F. Zhu, N. X. Wei, R. A. Javed and F. C. Jiang, "Fracture behavior of Ti/Al 3 Ti metal-intermetallic laminate (MIL) composite under dynamic loading," Mater. Sci. Eng., A, vol. 637, Apr. 2015, pp. 235-242, doi:10.1016/j.msea.2015.04.025.

[11] K. S. Vecchio, "Synthetic multifunctional metallic-intermetallic laminate composites," JOM, vol. 57, Jan. 2005, pp. 25-31, doi:10.1007/s11837-005-0229-4.

[12] E. H. Wang, Y. Tian, Z. Q. Wang, F. F. Jiao, C. H. Guo and F. C. Jiang, "A study of shape memory alloy NiTi fiber/plate reinforced (SMAFR/SMAPR) Ti-Al laminated composites," J. Alloys. Compd, vol. 696, Dec. 2017, pp. 1059-1066, doi: 10.1016/j.jallcom.2016.12.062

[13] A. Rohatgi, D. J. Harach, K. S. Vecchio and K. P. Harvey, "Resistance-curve and fracture behavior of $\mathrm{Ti}-\mathrm{Al} 3 \mathrm{Ti}$ metallicintermetallic laminate (MIL) composites," Acta. Mater, vol. 51, Jun. 2003, pp. 2933-2957, doi:10.1016/S1359-6454(03)00108-3.

[14] C, Pu, Y Gao. "Crystal plasticity analysis of stress partitioning mechanisms and their microstructural dependence in advanced steels." Journal of Applied Mechanics 82.3 (2015): 031003.

[15] C. Pu, Y. Gao, Y. Wang, T.L. Sham, Diffusion-coupled cohesive interface simulations of stress corrosion intergranular cracking in polycrystalline materials, Acta Mater 136(Supplement C) (2017) 21 31.

[16] C, Pu. "Failure simulations at multiple length scales in high temperature structural alloys." (2015).

[17] J He and F. Yuan. A quantitative damage imaging technique based on enhanced CCRTM for composite plates using 2D scan. Smart. Mater. Struct., 25(10):105022, 2016.

[18] J. He and F. Yuan. Lamb-wave-based two-dimensional areal scan damage imaging using reverse-time migration with a normalized zero-lag cross-correlation imaging condition. Struct. Health. Monit, 2016.

[19] H. I. Dawood, K. S. Mohammed, A. Rahmat and M. B. Uday, "Effect of small tool pin profiles on microstructures and mechanical properties of 6061 aluminum alloy by friction stir welding," Trans. Nonferrous. Met. Soc. China, vol. 25, Jun. 2015, pp. 2856-2865, doi:1016/S1003-6326(15)63911-5.

[20] R. S. Mishra and Z. Y. Ma, "Friction stir welding and processing," Mater. Sci. Eng., R, vol. 50, Sept. 2005, pp. 1-78, doi:10.1016/j.mser.2005.07.001.

[21] G. X. Zhou, L. X. Liu, Y. Q. Wang, S. Wang and L. Qiao, "Foundational study on relationship between deformation quantity and joining strength of rolled aluminum alloy laminated plates", Ordn. Mater. Sci. Eng, vol. 31, Jan. 2008, pp. 55-59, doi:10.14024/j.cnki.1004-244x.2008.01.016.

[22] Z. F. Liang, Q. Y. Shi and X. Kang, "Friction stir welding process parameter optimization of 7A52 aluminum alloy," Trans. China. Weld. Inst, vol. 32, Feb. 2011, pp. 17-20.

[23] T. Y. Li, F. R. Chen and Z. H. Zhang, "Effect of welding speed on microstructure and mechanical properties of 7A52 aluminum alloy by friction stir welding," J. Netsh. Form. Eng, vol. 7, Sept. 2015, pp. 7276, doi:10.3969/j.issn.1674-6457.2015.05.011.

[24] J. J. Zhao, Q. Li, Z. H. Cai and P. Zhang, "Effects of secondary phases on stress corrosion property of friction stir welded seam of 7A52 aluminum alloy under different strain rates," Trans. China. Weld. Inst, vol. 34, Aug. 2013, pp. 63-66.

[25] Z. F. Liang, Q. Y. Shi and X Kang, "Friction stir welding process parameter optimization of 7A52 aluminum alloy," Trans. China. Weld. Inst, vol. 32, Feb. 2011, pp. 17-20.

[26] H. W. Liu, J. L. Li, B. Ma and Q. Zhou, "Comparison of joint properties of 7A52 alloy welded by friction stir welding and double wire MIG," Hot. Work. Technol, vol. 40, May. 2011, pp. 117-119. 